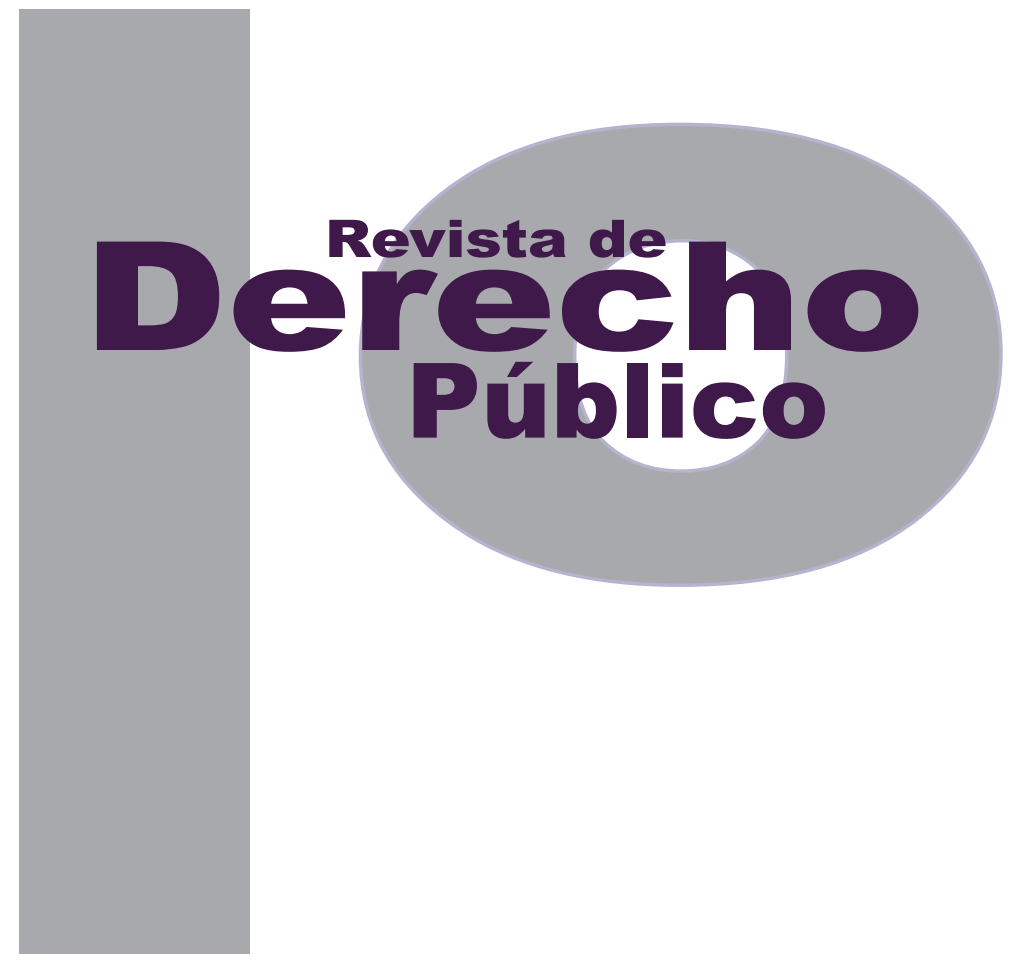

\title{
RESPONSABILIDAD DEL MUNICIPIO DE MEDELLÍN EN EL CASO DEL EDIFICIO SPACE
}

\author{
luisa Cecilia Flórez Ruiz
}

DOI: http://dx.doi.org/10.15425/redepub.33.2014.03

Universidad de los Andes

Facultad de Derecho

Revista de Derecho Público N. ${ }^{\circ} 33$

Julio - Diciembre de 2014. ISSN 1909-7778 


\title{
Responsabilidad del municipio de Medellín en el caso del edificio Space*
}

\author{
Luisa Cecilia Flórez Ruiz*
}

La responsabilidad por el incumplimiento de las condiciones de calidad e idoneidad en lo que concierne a defectos y a fallas de las estructuras de una construcción destinada a vivienda, no es solo del curador que otorga la licencia y del constructor que desarrolla la obra, sino también del municipio.

Todos hemos comentado la responsabilidad de la constructora CDO y del curador segundo en el fatídico caso del edificio Space, pero poco o casi nada se dice de la responsabilidad del municipio de Medellín.

Leyendo el artículo 63 del Decreto 1469 de 2010, Por el cual se reglamentan las disposiciones relativas a las licencias urbanísticas; al reconocimiento de edificaciones; a la función pública que desempeñan los curadores urbanos y se expiden otras disposiciones, vemos que establece expresamente:

Competencia del control urbano. Corresponde a los alcaldes municipales o distritales directa- mente o por conducto de sus agentes, ejercer la vigilancia y control durante la ejecución de las obras, con el fin de asegurar el cumplimiento de las licencias urbanísticas y de las normas contenidas en el Plan de Ordenamiento Territorial, sin perjuicio de las facultades atribuidas a los funcionarios del Ministerio Público y de las veedurías en defensa tanto del orden jurídico, del ambiente y del patrimonio y espacios públicos, como de los intereses colectivos y de la sociedad en general.

En todo caso, la inspección y seguimiento de los proyectos se realizará mediante inspecciones periódicas durante y después de la ejecución de las obras, de lo cual se dejará constancia en un acta suscrita por el visitador y el responsable de la obra.

Dichas actas de visita harán las veces de dictamen pericial, en los procesos relacionados por la violación de las licencias y se anexarán al Certificado de Permiso de Ocupación cuando fuere del caso.

Cómo citar esta reseña: Flórez Ruiz, L. C. (Diciembre, 2014). Responsabilidad del municipio de Medellín en el caso del edificio Space. Revista de Derecho Público, 33. Universidad de los Andes (Colombia).

* T. P. de abogado 33.220 del Consejo Superior de la Universidad de Antioquia. Correo: luisaceciliaflorezruiz066@gmail.com

Judicatura. Docente Facultad de Derecho y Ciencias Políticas 
Ante esta disposición jurídica surge la pregunta: ¿dónde se encuentran las actas suscritas por los visitadores técnicos que dieron cuenta del seguimiento a la construcción del edificio Space y del cumplimiento de la licencia en los términos en que se debió otorgar?, ¿en qué momento el municipio las enseñó a la opinión pública que reclamaba explicaciones?

Igualmente, el mencionado decreto en su artículo 53 exige al constructor que una vez terminada la obra debe obtener de la autoridad competente para ejercer el control urbano, es decir del municipio, el Certificado de Permiso de Ocupación, el cual consiste en un acta que certifica que la obra se construyó de conformidad con la licencia otorgada por el curador y con el cumplimiento de las normas de sismo resistencia y las normas urbanísticas y arquitectónicas.

Según esta norma, el municipio de Medellín incurrió en falta o falla del servicio porque no vigiló ni controló la construcción del edificio Space antes y después, dado que era su deber vigilar que en su ejecución la constructora cumpliera con todos los estándares y técnicas que establece la ingeniería para la construcción de obras como esta, de conformidad con las normas de sismo resistencia y con el Decreto 1469 de 2010.

El municipio de Medellín, según lo establece el decreto en mención, debió ejercer a través de Planeación Municipal el control anterior y posterior de la construcción del edificio Space. Parte del control posterior es el permiso de ocupación de los apartamentos, el cual no debió otorgar porque con ello llevó a sus habitantes no solo a la ruina, sino también a la muerte.

La reglamentación sobre el control de la construcción por parte de los municipios sí existe, y el hecho de que operen las curadurías no es excusa para que los entes locales se relajen frente a la responsabilidad que les ha atribuido expresamente el artículo 313 numeral 7 de la Constitución Nacional, el artículo 109 de la Ley 388 de 1997 y el Decreto 1469 de 2010 en sus artículos 63 y 53.

A la luz de la normatividad transcrita no solo el constructor y el curador que otorgó la licencia son responsables por la construcción defectuosa del edificio Space, sino también el municipio de Medellín por no verificar, antes de otorgar el permiso de ocupación, que la obra se hubiera ejecutado como se aprobó en la licencia y que cumpliera las normas de sismo resistencia, es decir, debió vigilar y controlar su construcción desde que inició hasta que se terminó y más allá.

Reitero: la responsabilidad por el incumplimiento de las condiciones de calidad e idoneidad en lo que concierne a defectos y a fallas de las estructuras de una construcción destinada a vivienda no es solo del curador que otorga la licencia y del constructor que desarrolla la obra, sino también del municipio, quien es el ente encargado de ejercer el control durante la ejecución y posteriormente de otorgar el permiso de ocupación de las viviendas. 